\title{
MANEJO PARA A RECUPERAÇÃO DE FORRAGEIRAS PERENES ESTIVAIS A DANOS POR GEADAS
}

\author{
Gustavo Krahl'1, Daison Henrique Marocco²
}

\begin{abstract}
RESUMO - Na região sul do Brasil, é frequente a ocorrência de geadas no inverno. Este evento climático pode provocar a morte das plantas, ou de suas partes. Portanto, o objetivo deste trabalho foi avaliar os danos por geada em cinco espécies/cultivares de forrageiras perenes estivais (Capim Áries, Convert HD364, Capim Tangola, Jiggs e Missioneira-gigante), bem como a recuperação das plantas na estação subsequente após a remoção ou não da massa de forragem previamente a ocorrência das geadas. O trabalho foi conduzido na Universidade do Oeste de Santa Catarina. No experimento de campo, ocorreram duas geadas, a primeira com moderada intensidade $\left(-2^{\circ} \mathrm{C}\right)$ e a segunda com baixa intensidade $\left(-0,5^{\circ} \mathrm{C}\right)$. Plantas em vasos foram submetidas a geadas artificiais em câmara BOD, com intensidade de $-2^{\circ} \mathrm{C}$ e $-4^{\circ} \mathrm{C}$. Previamente ao período de ocorrência de baixas temperaturas, perfilhos de cada cultivar foram marcados. Os danos nas folhas de cada perfilho foram avaliados sete dias após cada geada. O percentual de dano foi composto pelo dano médio das folhas de cada perfilho, avaliado de forma visual, sempre pelo mesmo avaliador. A espécie missioneira-gigante tem alta tolerância a geadas. Cultivares do gênero Brachiaria (Urochloa) apresentam reduzida tolerância a danos por geadas. Dentre as cultivares com boa tolerância a geadas estão a Jiggs e Áries, com ressalva a cultivares com hábito de crescimento cespitoso ereto, que podem apresentar dificuldades na cobertura de solo após a morte de plantas posterior a geadas severas. O manejo de remoção ou não da massa previamente a geada não impactou na população de perfilhos na estação subsequente. Mais trabalhos devem ser realizados em locais com maior frequência e intensidade de geadas para validar esta informação. A avaliação de danos por geadas em plantas forrageiras em ambiente controlado apresenta-se como alternativa viável para a definição de níveis de tolerância a este evento climático.
\end{abstract}

Palavras chave: Ambiente controlado, frio/geada, intensidade, resiliência, tolerância.

\section{MANAGEMENT FOR RECOVERING ESTIVAL PERENNIAL FORAGES FROM DAMAGES BY FROST}

BSTRACT - In the southern region of Brazil, frost is frequent in winter. This climatic event can cause death of plants, or parts thereof. Therefore, the objective of this work was to evaluate frost damage on five perennial summer forage species (Aries grass, Convert HD364 grass, Tangola grass, Jiggs grass, and Giant missionary grass), as well as the recovery of plants in the subsequent season after removal of the forage mass prior to the occurrence of frost. The work was conducted at the University of Western Santa Catarina. In the field experiment, two frosts occurred, the first with moderate intensity $\left(-2^{\circ} \mathrm{C}\right)$ and the second with low intensity $\left(-0.5^{\circ} \mathrm{C}\right)$. Potted plants were submitted to artificial frosts in a $\mathrm{BOD}$ chamber, with intensity of $-2^{\circ} \mathrm{C}$ and $-4^{\circ} \mathrm{C}$. Before the period of low temperatures, tillers of each cultivar were marked. The leaf damage of each tiller was evaluated seven days after each frost. The percentage of damage was composed by the average damage of the leaves of each tiller, evaluated visually, always by the same evaluator. The giant missionary grass species has high frost tolerance. Cultivars of the Brachiaria (Urochloa) species show reduced tolerance to frost damage. Among the cultivars with good tolerance to frost are Jiggs grass and Aries grass, with the exception of cultivars with erect cesspit growth habit, which may present difficulties in soil cover after the death of

\footnotetext{
${ }^{1}$ Universidade do Oeste de Santa Catarina, Curso de Zootecnia, Xanxerê - SC.

${ }^{2}$ Autor para correspondência: gustavo.zootecnista@live.com
} 
plants after severe frost. The removal or not of the mass prior to frost did not affect the tiller population in the subsequent season. More work should be done in places with greater frequency and intensity of frosts to validate this information. The evaluation of frost damage in forage plants in a controlled environment is a viable alternative for the definition of tolerance levels to this climatic event.

Keywords: controlled environment, cold, intensity, tolerance, resilience.

\section{INTRODUÇÃO}

Na região sul do Brasil, a ocorrência de geadas é frequente durante os meses de inverno. De acordo com Pereira (2002), a geada é um fenômeno atmosférico que provoca a morte das plantas, ou de suas partes, devido ao congelamento dos tecidos vegetais. Esse processo resulta na desidratação das células, perda do potencial de turgescência, redução do volume celular e plasmólise. Como resultado, as folhas ficam flácidas, inicialmente com coloração verde escura e posteriormente com coloração amarela (seca). As perdas nas forrageiras predominantes pode forçar o uso de suplementação volumosa e concentrada na alimentação do rebanho, onerando o custo de produção (Vilela \& Alvim, 1996).

O que se observa no estado de Santa Catarina, principalmente entre os produtores de leite, que espécies forrageiras exóticas são implantadas sem critérios definidos. Novas cultivares, muitas vezes desenvolvidas para outras regiões do Brasil, são tomadas como possíveis soluções à estacionalidade forrageira.

Ricce et al. (2016) em análise climática de 2015 e 2016 para o estado de Santa Catarina, confirmaram que o estado apresenta grande variabilidade climática, permitindo o desenvolvimento de um grande número de atividades agropecuárias. Porém, eventos climáticos atípicos, como frios e geadas tardias e excesso de chuvas, prejudicaram o desenvolvimento de várias culturas.

De acordo com Silveira \& Perez (2014), alguns dos fatores limitantes para o uso de pastagens cultivadas, principalmente com plantas forrageiras perenes C4, têm sido a persistência após o frio e as geadas comuns no inverno. Assim, observa-se que há a necessidade de encontrar plantas $\mathrm{C} 4$ para serem utilizadas no período de verão, mas que ao mesmo tempo se adaptem a condições adversas de inverno. No entanto, para as condições de frio intenso do Sul do Brasil, o número de materiais com informações disponíveis é reduzido.

Além da escolha de espécies e cultivares, podese lançar mão de práticas de manejo que minimizem ou evitem os danos causados por geadas, ou que permitam a recuperação para produção no ciclo produtivo posterior.
Observa-se que algumas práticas são amplamente estudadas em culturas de alto valor agregado, como frutíferas e hortaliças, porém com dificuldade de aplicação em pastagens.

De acordo com Snyder \& Melo-Abreu (2005), para proteção passiva contra geadas, é melhor remover toda a vegetação. A remoção de culturas de cobertura aumentará a absorção de radiação pelo solo, o que melhora a transferência e armazenamento de energia. Além disso, poderia reduzir a concentração de bactérias ativadoras de nucleação de gelo (INA), que por proporcionar maior chance de formação de gelo na superfície, podem potencializar o dano por geada.

De acordo com Clements et al. (2003), o dano por geada é mais severo em folhas mais velhas, mesmo em espécies mais tolerantes, em todos os casos reduzindo a qualidade da pastagem. Para Melo-Abreu \& Ribeiro (2010), as folhas e caules podem ser danificados e recuperar, mas quando o nó de perfilhamento é danificado a planta não recupera. Portanto, a recomendação de manter a cobertura em período que antecede a ocorrência de geada poderia proteger as gemas basilares e assim não prejudicar o perfilhamento da cultura na próxima estação.

No entanto, a massa acumulada antes do inverno pode ser considerada uma perda de matéria seca, e justamente poderia ser utilizada como forragem conservada no período de entressafra. Então, a decisão de manter ou remover a massa de forragem anteriormente a ocorrência de geadas é relativamente difícil.

Neste contexto, o objetivo deste trabalho foi avaliar os danos por geada em cinco espécies/cultivares de forrageiras perenes estivais, bem como a recuperação das plantas na estação subsequente após a remoção ou não da massa de forragem previamente a ocorrência das geadas.

\section{MATERIAL E MÉTODOS}

O trabalho foi conduzido no campo agrostológico e no laboratório de biotecnologia da Universidade do Oeste de Santa Catarina - UNOESC, campus de Xanxerê. A $26^{\circ}$ 52' 37” de latitude S, $52^{\circ} 24^{\prime} 15^{\prime}$ ” de longitude W e altitude 
de $800 \mathrm{~m}$. O clima do local é do tipo Cfa (Koeppen), subtropical (mesotérmico úmido com verão quente), com temperatura média anual entre 16 e $17^{\circ} \mathrm{C}$ e precipitação média de 2.100 a 2.300 mm por ano (Santa Catarina, 2003).

Cinco cultivares de forrageiras perenes estivais foram selecionadas para a avaliação dos danos por geadas e influência no manejo na respectiva recuperação. Avaliouse o Capim Áries (Panicum maximum), Convert HD364 (híbrido do gênero Brachiaria (Urochloa)), Capim Tangola (Brachiaria (Urochloa) arrecta x Brachiaria (Urochloa) mutica), Jiggs (Cynodon dactylon) e Missioneira-gigante (Axonopus catharinensis). A escolha foi baseada em levantamento das espécies forrageiras mais utilizadas em pastagens na Região Oeste de Santa Catarina (Jochims et al., 2017).

A semeadura (Convert HD364 e Áries) e o plantio das mudas (Tangola, Jiggs e Missioneira-gigante), foram realizados no dia 21 de outubro de 2017 em canteiros com $6 \mathrm{~m}^{2}$, em Latossolo Vermelho distrófico típico e textura argilosa (Embrapa, 1999). O solo foi corrigido de acordo com análise, conforme indicação para forrageiras no Manual de adubação e calagem para os estados de Santa Catarina e Rio Grande do Sul (CQFS-RS/SC, 2016).

Os canteiros foram conduzidos com roçadas periódicas no momento em que o dossel forrageiro atingia altura meta de manejo para cada cultivar. Para Capim Áries $30 \mathrm{~cm}$, Convert HD364, Tangola e Missioneira-gigante $25 \mathrm{~cm}$ e Jiggs $20 \mathrm{~cm}$. A primeira roçada foi realizada com severidade de aproximadamente $75 \%$ para estimular o perfilhamento e cobertura da área. A altura meta inicial foi rebaixada em torno de $50 \%$ a altura meta de entrada em cada roçada. Após a ocorrência da primeira geada metade da área das unidades experimentais foram roçadas (Tabela 1), considerando que ocorreriam novas geadas na área. Portanto, os manejos aplicados foram, corte com alta severidade (AS) e sem corte (SC) previamente a ocorrência de geadas. Após 90 dias da ocorrência da última geada realizou-se contagem de perfilhos para verificação da resposta das plantas as geadas e aos manejos aplicados.

Previamente ao período de ocorrência de baixas temperaturas, vinte perfilhos de cada cultivar foram marcados com arames plastificados de coloração branca, e sinalizados com vareta de madeira e numeração sequencial para facilitar a visualização e registro das informações. Os danos nas folhas de cada perfilho foram avaliados sete dias após cada geada. Ocorreram duas geadas no local de avaliação, a primeira em 08 de junho de 2018, com intensidade moderada $\left(-2^{\circ} \mathrm{C}\right)$ e a segunda ocorrida em 12 de julho de 2018, com baixa intensidade $\left(-0,5^{\circ} \mathrm{C}\right)$. O percentual de dano foi composto pelo dano médio das folhas de cada perfilho, avaliado de forma visual, sempre pelo mesmo avaliador (Figura 1).

Tabela 1 - Alturas de manejo aplicadas no início do período de ocorrência de geadas

\begin{tabular}{lccc}
\hline \multicolumn{1}{c}{ Cultivar } & $\begin{array}{c}\text { Altura pré } \\
\text { corte }{ }^{1}, \mathrm{~cm}\end{array}$ & $\begin{array}{c}\text { Altura pós } \\
\text { corte, cm }\end{array}$ & $\begin{array}{c}\text { Severidade, } \\
\%\end{array}$ \\
\hline Áries & $36,5 \pm 4,0$ & $8,5 \pm 1,5$ & 76,7 \\
Convert HD364 & $20,8 \pm 3,8$ & $5,7 \pm 2,1$ & 72,8 \\
Capim Tangola & $14,2 \pm 3,8$ & $4,1 \pm 1,5$ & 71,0 \\
Jiggs & $16,7 \pm 3,9$ & $5,1 \pm 1,5$ & 69,7 \\
$\begin{array}{l}\text { Missioneira- } \\
\text { gigante }\end{array}$ & $14,7 \pm 3,8$ & $4,0 \pm 1,2$ & 73,1 \\
\hline Média & $20,6 \pm 3,9$ & $5,5 \pm 1,6$ & 72,7 \\
\hline
\end{tabular}

${ }^{1}$ Corte realizado com roçadeira costal e a massa cortada removida da área experimental.
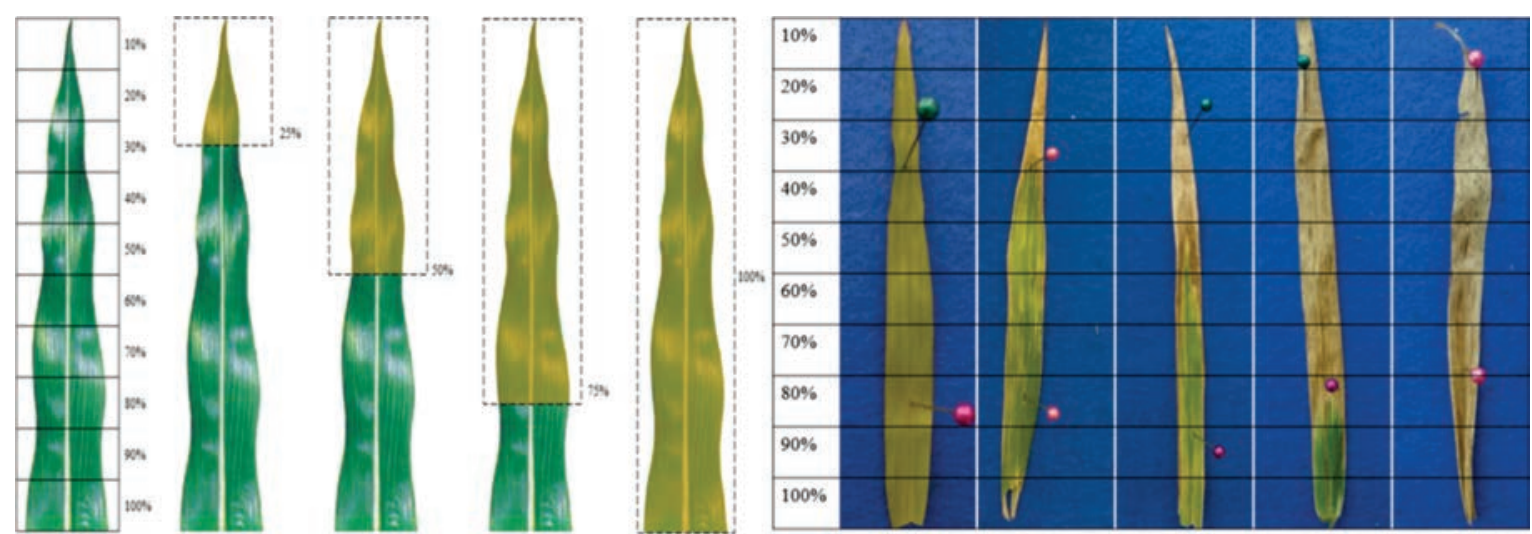

Figura 1 - Padrão de avaliação do dano por geada nas lâminas foliares 7 dias após a ocorrência do evento climático. 
A temperatura de relva foi registrada por termômetro de mínima e máxima localizado na altura do dossel forrageiro. Adicionalmente, as condições de temperatura do ar, ponto de orvalho e velocidade do vento foram monitoradas em tempo real por estação meteorológica localizada a aproximadamente $50 \mathrm{~m}$ do experimento.

O experimento a campo foi conduzido em delineamento inteiramente casualizado, em arranjo fatorial $5 \times 2$ (5 cultivares de forrageiras x 2 manejos), com vinte repetições para avaliar danos na primeira geada e dez repetições para avaliação da segunda geada e de cada manejo.

Adicionalmente, testou-se metodologia de avaliação de dano por geada produzida artificialmente, em duas intensidades $\left(-2,0\right.$ e $\left.-4,0^{\circ} \mathrm{C}\right)$. A semeadura e o plantio foram realizados em vasos com capacidade de 0,5 L, com o mesmo solo do experimento a campo. A implantação foi ajustada para que cada unidade experimental possuísse três perfilhos no momento das avaliações. A irrigação dos vasos foi realizada diariamente, no início do estabelecimento das plantas e posteriormente o solo foi mantido próximo à capacidade de campo, por meio da reposição diária do consumo de água.

A simulação de geada foi realizada em câmara de crescimento BOD, com intensidade máxima de luz de $1.225 \mu \mathrm{mol} \mathrm{m}{ }^{-2} \mathrm{~s}^{-1}$, temperatura de -10 a $50^{\circ} \mathrm{C}$, com precisão de $\pm 0,5^{\circ} \mathrm{C}$. No primeiro dia de adaptação, as plantas foram mantidas 24 horas na câmara em temperatura máxima de $18^{\circ} \mathrm{C}$ e mínima de $12^{\circ} \mathrm{C}$. No segundo dia de adaptação, as plantas foram mantidas 24 horas em temperatura máxima de $12^{\circ} \mathrm{C}$ e mínima de $2^{\circ} \mathrm{C}$. No dia de aplicação da geada artificial, as plantas foram mantidas em temperatura máxima de $12^{\circ} \mathrm{C}$ e com mínima de $-2,0$ ou $-4,0^{\circ} \mathrm{C}$ (metas), com taxa de redução de $2^{\circ} \mathrm{C}$ por hora até a temperatura mínima e posteriormente $2^{\circ} \mathrm{C}$ até a temperatura de $12^{\circ} \mathrm{C}$.

As plantas foram umidificadas com água fria quando a temperatura atingiu $2^{\circ} \mathrm{C}$ de diferença em relação a temperatura mínima meta, com o auxílio de um borrifador. O processo de umidificação teve por finalidade incitar a formação de cristais de gelo nas superfícies expostas das plantas e simular a formação de geada. As plantas foram mantidas por período de 1 hora em temperatura de -2 ou $-4^{\circ} \mathrm{C}$.

No experimento em ambiente controlado foram avaliadas as 5 cultivares, com 6 vasos cada cultivar e 3 perfilhos por vaso, totalizando 90 unidades experimentais. Outro conjunto de 15 vasos, com 3 vasos para cada cultivar e três perfilhos por vaso, foi preparado para receber ao menos uma geada natural. Estes vasos foram acometidos pela geada ocorrida em 08 de junho de 2018, com intensidade moderada $\left(-2^{\circ} \mathrm{C}\right)$, e os danos avaliados sete dias após. Este procedimento foi realizado com o objetivo de comparação da incidência de danos nas plantas acometidas por geadas em diferentes metodologias (dossel forrageiro à campo, em vasos à campo e em vasos com ambiente controlado).

A definição do regime de aclimatação para a geada artificial foi baseada em Wendt \& Rosa (1989) e nas temperaturas definidas para os tipos climáticos $\mathrm{Cfa}$ e $\mathrm{Cfb}$ (Koeppen). O regime de geada foi definido com base em estudo prévio da climatologia das geadas, em que $12^{\circ} \mathrm{C}$ foi a temperatura máxima nos dias de ocorrência do evento climático (Silva et al., 2008).

Os dados dos experimentos a campo e em ambiente controlado foram submetidos ao teste de normalidade e, quando atendida esta pressuposição $(\mathrm{P}>0,05)$, foi realizada análise de variância. Dados que não apresentaram distribuição normal $(\mathrm{P}<0,05)$ foram submetidos a transformação de Box-Cox e posteriormente ao teste de normalidade. Quando verificado efeito $(\mathrm{P}<0,05)$ dos danos nas diferentes cultivares e efeito dos locais (à campo no dossel forrageiro, à campo em vasos e em ambiente controlado, todos com temperatura de $-2{ }^{\circ} \mathrm{C}$ ), as médias foram comparadas pelo teste de Tukey a $5 \%$.

Os dados de danos provocados por geadas de diferentes intensidades $\left(-0,5^{\circ} \mathrm{C},-2^{\circ} \mathrm{C}\right.$ e $\left.-4^{\circ} \mathrm{C}\right)$, foram submetidos a análise variância e de regressão linear ou quadrática, de modo que o modelo escolhido foi aquele que melhor se ajustou aos dados obtidos.

\section{RESULTADOS E DISCUSSÃO}

As temperaturas mínimas registradas no abrigo nas duas geadas ocorridas foram $4,4^{\circ} \mathrm{C}$ e $6,3^{\circ} \mathrm{C}$, em que as temperaturas mínimas de relva foram $-2,0^{\circ} \mathrm{C}$ e $-0,5^{\circ} \mathrm{C}$, respectivamente. As diferenças entre temperatura de abrigo e de relva nas duas geadas foram $6,4^{\circ} \mathrm{C}$ e $6,8^{\circ} \mathrm{C}$, respectivamente. Estes valores ficaram acima dos observados em diferentes locais da região sul do Brasil. De acordo com Silva \& Sentelhas (2001), a variação de 2,1 a $4,8^{\circ} \mathrm{C}$, entre as localidades de Santa Catarina. Para o estado do Paraná, a diferença média de temperatura medida no abrigo meteorológico e a relva foi de $5^{\circ} \mathrm{C}$, onde foram constatados gradientes médios de temperatura mínima entre o abrigo e a relva variando de 4,2 a $6,3^{\circ} \mathrm{C}$ nas regiões analisadas (Vieira Junior et al., 2018).

A temperatura registrada no abrigo meteorológico pode indicar a ocorrência de dano em culturas, considerando-se temperaturas de $2^{\circ} \mathrm{C}$ a $3^{\circ} \mathrm{C}$ como limites abaixo dos quais se iniciam os danos. Porém, o registro da 
temperatura a $5 \mathrm{~cm}$ do solo pode indicar a condição real da geada com melhor precisão (Silva \& Sentelhas, 2001).

Apesar de ser importante ferramenta para monitoramento imediato das ocorrências de geada, a temperatura registrada no abrigo ou até mesmo na altura do dossel forrageiro, não possibilitam impedir os danos por este evento climático em pastagens na maioria das condições. Em algumas situações, a irrigação estratégica poderia impedir maiores danos, porém, não existe informações sobre a área de pastagens irrigadas em Santa Catarina, além disso, o problema com secas são pontuais no estado e muitas vezes não justificam o investimento em irrigação.

Fica evidente que em pastagens, a minimização dos danos por geadas deve considerar outras alternativas, como por exemplo a escolha de espécies e cultivares com maior resistência e resiliência, e identificação de áreas com maior e menor incidência de geadas na própria propriedade (baixadas úmidas, encostas, áreas de altitude, etc.). Na região Sul, onde a técnica de sobressemeadura de espécies forrageiras anuais hibernais sobre pastagens perenes estivais é amplamente utilizada, a geada é indispensável para impedir que a forrageira estival dificulte a germinação e produção da forrageira hibernal. Porém neste caso, a resiliência da espécie da forrageira perene estival é imprescindível para o sucesso do sistema produtivo baseado em pastagens.

Na Tabela 2 estão apresentados os resultados de dano por geada em lâminas foliares das cultivares forrageiras avaliadas, separadamente para cada geada e de forma conjunta. Observa-se que praticamente não houve danos por geada na grama Missioneira-gigante, ou baixa proporção de danos mesmo com temperatura de $-4^{\circ} \mathrm{C}$, o que confirma a característica de tolerância ao frio já atribuídas a espécie (Hanisch et al., 2016).

Tabela 2 - Dano por geada de diferentes intensidades e diferentes metodologias em lâminas foliares de cinco espécies forrageiras perenes estivais

\begin{tabular}{lcccccc}
\hline \multirow{2}{*}{ Espécie } & \multicolumn{3}{c}{ Temperatura de relva, ${ }^{\circ} \mathrm{C}$} & \multicolumn{2}{c}{ Dano } \\
\cline { 2 - 5 } & $-0,5^{*}$ & $-2,0^{1}$ & $-2,0^{2}$ & $-2,0^{3}$ & $-4,0^{* *}$ & Médio \\
\hline Missioneira-gigante & $0,0 \mathrm{~b}$ & $0,0 \mathrm{~d}$ & $0,0 \mathrm{~b}$ & $3,5 \mathrm{~d}$ & $9,1 \mathrm{~d}$ & $2,5 \mathrm{e}$ \\
Jiggs & $1,6 \mathrm{~b}$ & $32,6 \mathrm{c}$ & $32,1 \mathrm{a}$ & $5,0 \mathrm{~d}$ & $41,2 \mathrm{c}$ & $22,5 \mathrm{~d}$ \\
Áries & $13,2 \mathrm{~b}$ & $28,8 \mathrm{c}$ & $29,8 \mathrm{a}$ & $36,9 \mathrm{c}$ & $76,6 \mathrm{~b}$ & $37,1 \mathrm{c}$ \\
Convert HD364 & $29,9 \mathrm{a}$ & $59,1 \mathrm{~b}$ & $0,28 \mathrm{~b}$ & $69,5 \mathrm{~b}$ & $64,1 \mathrm{~b}$ & $44,6 \mathrm{~b}$ \\
Tangola & $37,3 \mathrm{a}$ & $83,9 \mathrm{a}$ & $43,7 \mathrm{a}$ & $88,6 \mathrm{a}$ & $98,1 \mathrm{a}$ & $70,3 \mathrm{a}$ \\
Média & 16,4 & 40,9 & 21,2 & 40,7 & 57,8 & - \\
P-valor & $<0,001$ & $<0,001$ & $<0,001$ & $<0,001$ & $<0,001$ & $<0,001$ \\
Erro padrão da média & 2,19 & 3,41 & 3,38 & 4,46 & 3,87 & - \\
\hline
\end{tabular}

Médias seguidas de letra minúsculas na mesma coluna não diferem entre si $(\mathrm{P}>0,05) ;{ }^{1} 1^{\circ}$ Geada ocorrida em 08 de junho de 2018 , temperatura mínima $-2^{\circ} \mathrm{C} ; * 2^{\circ}$ Geada ocorrida em 12 de julho de 2018 , temperatura mínima $-0,5^{\circ} \mathrm{C} ;{ }^{2}$ Avaliação em vasos com geada natural ocorrida em 08 de junho de 2018 , temperatura mínima de $-2{ }^{\circ} \mathrm{C} ;{ }^{3}$ Avaliação em vasos com geada artificial em ambiente controlado, temperatura mínima de $-2^{\circ} \mathrm{C}$; $* *$ Avaliação em vasos com geada artificial em ambiente controlado, temperatura mínima de $-4^{\circ} \mathrm{C}$.

A Figura 2B mostra uma característica importante que pode explicar os resultados obtidos com as geadas naturais. Observou-se que houve menor acúmulo de gelo sobre as plantas de Missioneira-gigante. Características de ângulo de inclinação das folhas, associadas as características da lâmina foliar, a concentração de bactérias ativadoras de nucleação de gelo (INA) e a influência destas no acúmulo de orvalho e ou o seu congelamento, devem ser objeto de estudo para elucidar este comportamento.

Observou-se maior proporção de dano nas lâminas foliares nas cultivares do gênero Brachiaria (Urochloa), Convert HD364 e Tangola. No Brasil, pesquisas são desenvolvidas para identificar gêneros, espécies e ecotipos de plantas forrageiras que sejam adaptadas às condições dos diversos ecossistemas, executadas na forma de coletas e intercâmbios de germoplasma exótico, principalmente do continente africano (Batista \& Godoy, 2000). As cultivares pertencentes ao gênero Brachiaria (Urochloa) têm uma posição de destaque na pecuária brasileira por tornarem possível a produção de carne e leite em solo de fertilidade baixa, porém, as braquiárias utilizadas até o momento, são plantas pouco tolerantes a baixas temperaturas, não sendo indicadas para regiões onde ocorrem geadas fortes (Ribeiro et al., 2016). 

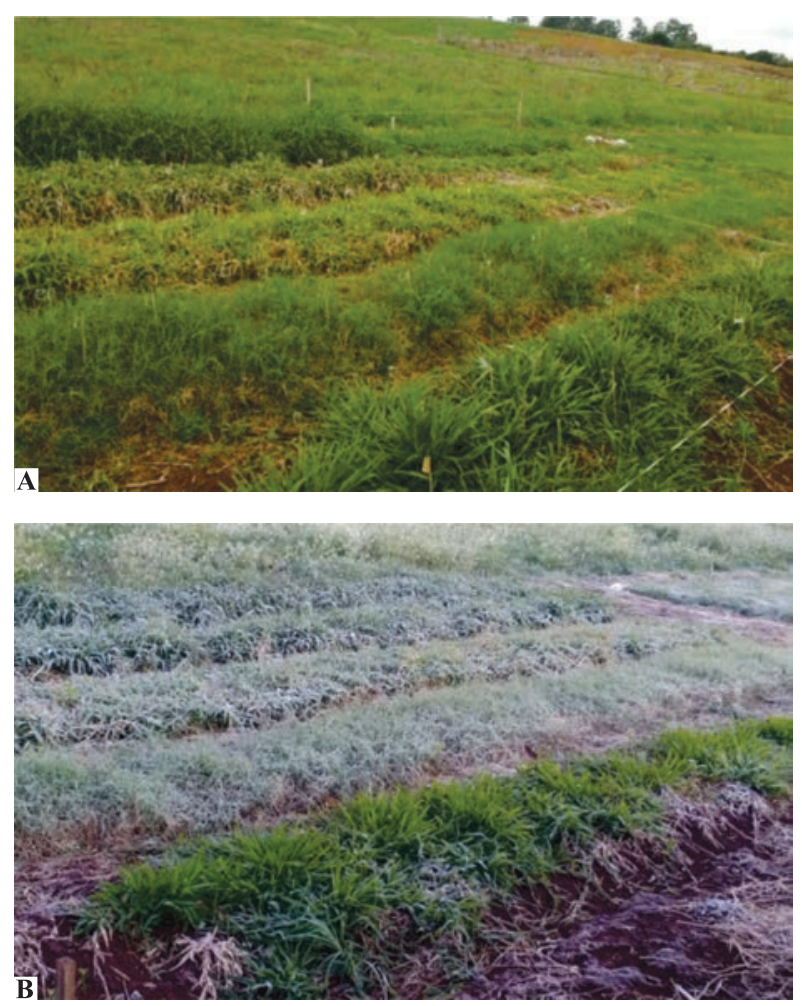

Figura 2 - Área experimental pré (A) e pós (B) ocorrência da primeira geada (ocorrida em 08 de junho de 2018).

As cultivares Áries e Jiggs apresentaram dano máximo de aproximadamente $30 \%$ das lâminas foliares, observado após a ocorrência da geada natural mais severa $\left(-2^{\circ} \mathrm{C}\right)$. Não apresentaram diferença entre si em nenhuma das geadas naturais. O capim Áries, dentre as cultivares do gênero Panicum, é considerado material forrageiro tolerante ao frio (Coimbra, 2016). Embora as informações científicas sejam escassas, é uma característica mencionada por pecuaristas e materiais comerciais de divulgação.

De acordo com avaliações em alguns centros de pesquisa localizados nos Estados Unidos, várias cultivares do gênero Cynodon tem tolerância ao frio (Corriher \& Redmon, 2011). Ensaios de variedades provaram que a Jiggs é tão tolerante ao frio como muitos dos cultivares de bermudas comerciais, e se assemelhou ao Tifton 85 no acúmulo de forragem na estação fria.

A Figura 3A mostra os danos por geadas no conjunto das cultivares avaliadas a partir dos manejos realizados, já que não houve interação entre cultivar e manejo $(\mathrm{P}>0,05)$. Observou-se que a remoção da massa por corte, aplicando-se alta severidade (72,7\%), pode aumentar o dano nas folhas na próxima geada $(\mathrm{P}=0,053)$. Neste caso, a primeira geada ocorreu 34 dias após a realização do corte, portanto houve tempo e condições climáticas mínimas para o rebrote e aparecimento de folhas.

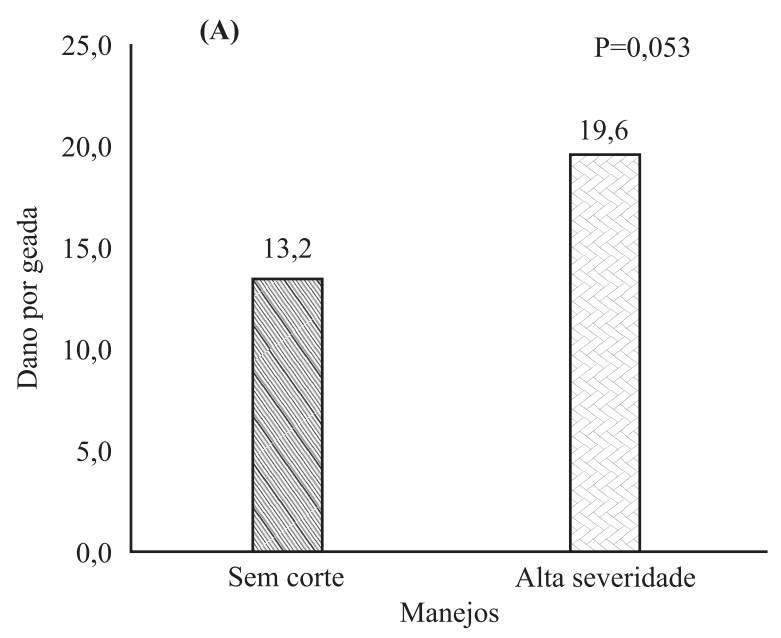

Figura 3A - Dano causado por geada (\% das lâminas foliares) $\left(-0,5^{\circ} \mathrm{C}\right.$, ocorrida em 12 de julho de 2018) em espécies forrageiras perenes estivais em dois manejos $(\mathrm{P}=0,053)$.

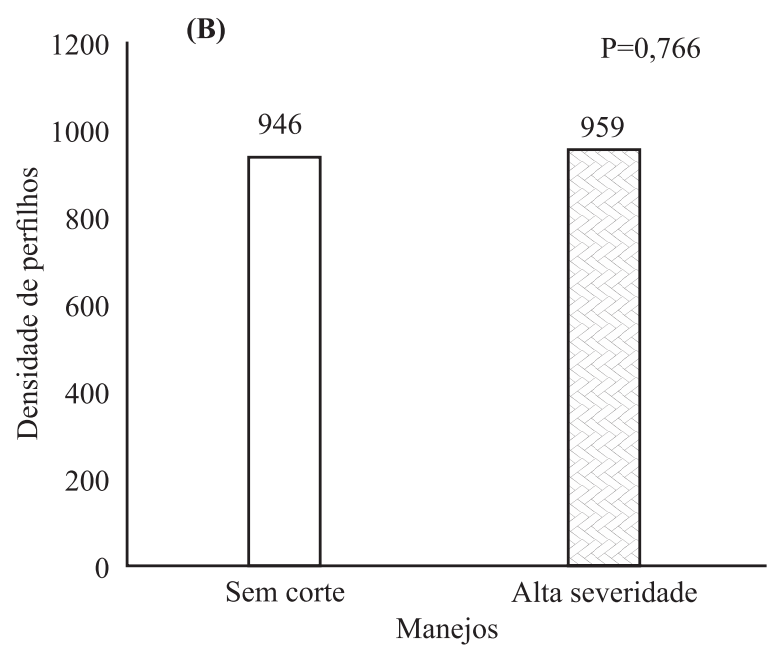

Figura 3B - Densidade de perfilhos (perfilho $\mathrm{m}^{-2}$ ) após 60 dias da ocorrência da geada $\left(-0,5^{\circ} \mathrm{C}\right.$, ocorrida em 12 de julho de 2018) em espécies forrageiras perenes estivais em dois manejos $(\mathrm{P}=0,766)$. 
Diferente de Clements et al. (2003), que afirmaram que o dano por geada é mais severo em folhas mais velhas, mesmo em espécies mais tolerantes às geadas, neste caso o dano foi maior em folhas mais jovens. O teor de matéria seca das folhas originadas posteriormente ao corte provavelmente era menor (dado não avaliado), logo, a maior proporção de dano pode ser explicada pela formação de gelo intra e extracelular provocar a ruptura das membranas celulares, levando a célula a morte. De acordo com Single (1971) citado por Scheeren (1982), este dano está associado aos tecidos jovens e poderá ser maior se a temperatura cair rapidamente.

A Figura 3B mostra a densidade populacional de perfilhos no conjunto das cultivares avaliadas a partir dos manejos realizados, já que não houve interação entre cultivar e manejo $(\mathrm{P}>0,05)$ para esta variável. Observa-se que a densidade de perfilhos foi semelhante $(\mathrm{P}=0,766)$, independente do manejo aplicado. Tendo em vista que a severidade das geadas foi baixa $\left(-2^{\circ} \mathrm{C}\right.$ e $\left.-0,5^{\circ} \mathrm{C}\right)$, não ocorreu mortalidade de plantas, apenas danos nas folhas. Adicionalmente, mesmo que a roçada tenha sido realizada com alta severidade, esperava-se a ocorrência de maior número de geadas e também num intervalo de tempo menor. A segunda e última geada ocorreu apenas 34 dias após a primeira, possibilitando crescimento das plantas e consequente proteção das gemas basilares, responsáveis pelo perfilhamento subsequente.

Pode-se ressaltar que o inverno do ano de 2018 na região oeste de Santa Catarina, bem como no município de Xanxerê foi atípico. De acordo com registros meteorológicos históricos, o número médio de ocorrência de geadas foi dezesseis (16) por ano, no período de 1983 a 2003 (Aguiar \& Mendonça, 2004). Novas avaliações em regiões do estado onde existe maior chance de ocorrência de geadas e com maior severidade poderão contribuir com novos resultados. Avaliações em ambientes controlados e com simulação de geadas podem ser alternativas viáveis para o estudo.

Observa-se na Figura 4 que o dano geral causado nas forrageiras é semelhante $(\mathrm{P}=0,006)$ entre as plantas no dossel forrageiro em ambiente natural e plantas em vasos em ambiente controlado com geada artificial. Isso demonstra que a metodologia utilizada para simular a geada em ambiente controlado pode ser validada para a representação deste evento em ambiente natural, tendo em vista a dificuldade de implantação e condução de experimentos a campo, e a dependência de ocorrência de geadas naturais. Plantas em vasos para avaliação de geadas naturais pode ser uma alternativa viável para algumas cultivares, porém, mantémse a dependência da ocorrência natural da geada.

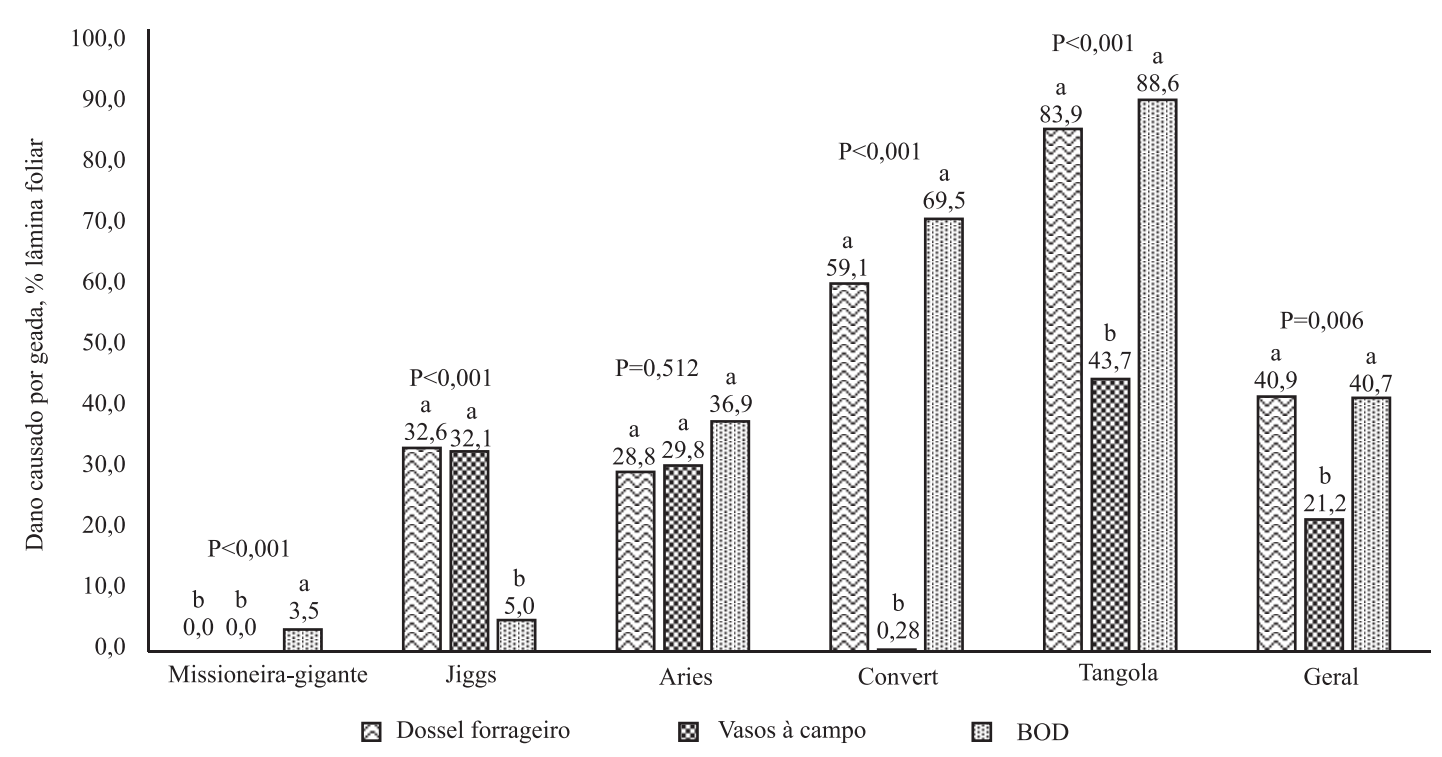

Figura 4 - Dano causado por geada (ocorrida em 08 de junho de 2018, temperatura mínima $-2^{\circ} \mathrm{C}$ ) em espécies forrageiras perenes estivais avaliadas no dossel forrageiro e em vasos à campo, e geada em ambiente artificial, temperatura mínima $-2^{\circ} \mathrm{C}$. 
As plantas no dossel forrageiro apresentaram duas características que podem explicar o maior dano quanto comparado aos vasos, mesmo recebendo a mesma geada. Nos vasos, a presença de apenas três perfilhos em cada cultivar proporcionava maior área de solo exposto, a absorção de radiação pelo solo pode melhorar a transferência e armazenamento de energia, reduzindo a formação de gelo na superfície das folhas. A maior quantidade de massa no dossel forrageiro, além de acumular maior quantidade de orvalho, pode servir de local para maior concentração de bactérias ativadoras de nucleação de gelo (INA), que por proporcionar maior chance de formação de gelo na superfície, podem potencializar o dano por geada (Snyder \& Melo-abreu, 2005).

Quando cada cultivar é avaliada individualmente, observa-se que Áries, Convert HD364 e Tangola, apresentaram danos semelhantes $(\mathrm{P}>0,05)$ quando se compara a geada natural no dossel forrageiro e geada artificial em ambiente controlado. A Missioneira-gigante apresentou diferença $(\mathrm{P}<0,001)$ entre as geadas ocorridas em dossel e ambiente controlado, porém a proporção de dano é biologicamente irrisória. A única cultivar que apresentou ampla diferença entre os métodos foi a Jiggs $(\mathrm{P}<0,001)$. Novas avaliações devem ser realizadas com cultivares do gênero Cynodon para esclarecer esta diferença.

A Figura 5 mostra a relação da temperatura das geadas e os danos causados nas lâminas foliares dos perfilhos, independentemente do local (ambiente natural ou controlado) ou da metodologia avaliada para a formação da geada (natural ou artificial). No conjunto das cultivares avaliadas o dano aumentou $(\mathrm{P}=0,029)$ com a redução da temperatura mínima durante a ocorrência do evento climático.

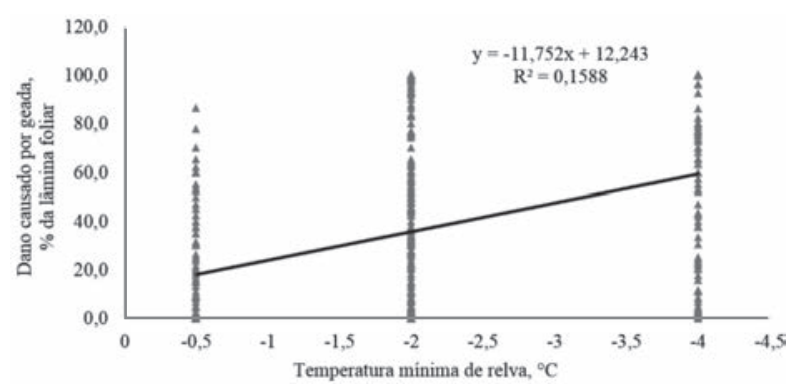

Figura 5 - Danos por geadas em lâminas foliares de cultivares de forrageiras perenes estivais em diferentes temperaturas intensidades (-0,5 geada natural em dossel forrageiro; -2,0 geada natural em dossel forrageiro, vasos à campo e geada artificial em ambiente controlado; $-4,0$ geada artificial em ambiente controlado).
As geadas artificiais foram utilizadas para avaliações em culturas hibernais e destinadas principalmente para a produção de grãos (Silva et al., 2008; Dalmago et al., 2010), mas existe coerência dos resultados com a aplicação de geadas artificiais em forrageiras cultivadas em vasos, demonstrando ser uma metodologia aplicável para estudos de efeitos das geadas em pastagens.

\section{CONCLUSÕES}

1. A espécie Missioneira-gigante tem alta tolerância a geadas. Cultivares do gênero Brachiaria (Urochloa), principalmente a Tangola, apresentam reduzida tolerância a danos por geadas. Dentre as cultivares com boa tolerância a geadas estão a Jiggs e Áries, com ressalva a cultivares com hábito de crescimento cespitoso ereto, que podem apresentar dificuldades na cobertura de solo após a morte de plantas posterior a geadas severas.

2. A remoção ou não da massa no período que antecede a ocorrência de geadas não impactou na população de perfilhos na estação subsequente. Mais trabalhos devem ser realizados em locais com maior frequência e intensidade de geadas para validar esta informação.

3. A avaliação de danos por geadas em plantas forrageiras em ambiente controlado apresenta-se como alternativa viável para a definição de níveis de tolerância a este evento climático.

\section{AGRADECIMENTOS}

Ao Programa de Bolsas de Estudo da Educação Superior - UNIEDU, da Secretaria do Estado de Santa Catarina, pela concessão de bolsa de estudo através do EDITAL N $14 / \mathrm{UNOESC}-\mathrm{R} / 2017$.

\section{LITERATURA CITADA}

AGUIAR, D.; MENDONÇA, M. Climatologia das geadas em Santa Catarina. In: SIMPÓSIO BRASILEIRO DE DESASTRES NATURAIS, 2004. Anais... Florianópolis: GEDN/UFSC, 2004. (CD-ROM).

BATISTA, L.A.R.; GODOY, R. Caracterização Preliminar e Seleção de Germoplasma do Gênero Paspalum para Produção de Forragem. Revista Brasileira de Zootecnia, v. 29, n.1, p.23-32, 2000.

CLEMENTS, B.; AYRES, L.; LANGFORD, C. et al. The Graziers Guide to Pastures, NSW Department of Primary Industries, Orange. 2003. In: Https://www.dpi.nsw.gov. 
au/__data/assets/pdf_file/0006/87270/graziers-guidepastures-full-version.pdf (acessado em 15 de janeiro de 2019).

COIMBRA, C.H.G. Métodos de preparo de solo e semeadura de Panicum maximum cv. áries e o consórcio com forrageiras hibernais. Tese (Doutorado em ciências). Curitiba, PR: UFPR, 2016. 83p.

COMISSÃO DE QUÍMICA E FERTILIDADE DO SOLO. Manual de calagem e adubação para os estados do Rio Grande do Sul e de Santa Catarina. 11. ed. Porto Alegre: Sociedade Brasileira de Ciência do Solo, Núcleo Regional Sul, Comissão de Química e Fertilidade do Solo - RS/SC, 2016. 376p.

CORRIHER, V. A; REDMON, L. A. Bermudagrass varieties, hybrids, and blends for Texas. 2011. In: Https:// agrilifecdn.tamu.edu/overton/files/2012/08/Bermudagrass. pdf (acessado em 05 de fevereiro de 2019).

DALMAGO, G.A.; CUNHA, G.R.; SANTI, A. et al. Aclimatação ao frio e dano por geada em canola. Pesquisa Agropecuária Brasileira, v.45, n.9, p.933-943, 2010.

EMBRAPA. Sistema brasileiro de classificação de solos. Brasília: Embrapa Produção de Informação; Rio de Janeiro: Embrapa Solos, 1999. 412p.

HANISCH, A.L.; DALGALLO, D. ALMEIDA, E.X. et al. Desempenho e composição química de missioneira-gigante cultivada em sistema silvipastoril tradicional em duas alturas de pastejo. Revista de Ciências Agrárias, v.59, n.4, p.345-351, 2016.

JOCHIMS, F.; SILVA, A.W.L.; PORTES, V.M. Espécies forrageiras mais utilizadas em pastagens na Região Oeste de Santa Catarina. Agropecuária Catarinense, v.30, n.3, p.15-18, 2017.

MELO-ABREU, J.P.; RIBEIRO, A.C. Os danos de geada: conceitos, mecanismos e modelos de simulação. In: FIGUEIREDO, T.; RIBEIRO, L.F.; RIBEIRO, A.C.; FERNANDES, L.F. Clima e recursos naturais. Bragança: Instituto Politécnico, 2010. p.141-166.

PEREIRA, A.R.; ANGELOCCI, L.R.; SENTELHAS, P.C. Agrometeorologia: fundamentos e aplicações práticas. Guaíba: Livraria e Editora Agropecuária, 2002. 478p.

RIBEIRO, T.B.; LIMA, W.M.; RIBEIRO, F.M. et al. Características forrageiras de algumas gramíneas do gênero Brachiaria - Revisão de literatura. Nutritime Revista Eletrônica, v.13, n.4, p.4773-4780, 2016.
RICCE, W.S.; MASSIGNAM, A.M.; PANDOLFO, C. et al. Análise climática de julho de 2015 a junho de 2016 para o Estado de Santa Catarina. In: EPAGRI/CEPA. Síntese Anual da Agricultura de Santa Catarina 2015 - 2016. Florianópolis: CEPA, 2016. p.167-173.

SANTACATARINA. Secretaria de Estado de Planejamento, Orçamento e Gestão. Xanxerê: Caracterização regional. 2003. In: http://docweb.epagri.sc.gov.br/website_cepa/ publicacoes/diagnostico/XANXERE.pdf. (acessado em 17 de janeiro de 2019).

SCHEEREN, P.L. Danos de geada em trigo: avaliação preliminar de cultivares. Pesquisa Agropecuária Brasileira, v.17, n.6, p.853-858, 1982.

SILVA, E.P.; CUNHA, G.R.; PIRES, J.L.F. et al. Fatores abióticos envolvidos na tolerância de trigo à geada. Pesquisa agropecuária brasileira, v.43, n.10, p.1257-1265, 2008.

SILVA, J.G.; SENTELHAS, P.C. Diferença de temperatura mínima do ar medida no abrigo e na relva e probabilidade de sua ocorrência em eventos de geada no Estado de Santa Catarina. Revista Brasileira de Agrometeorologia, v.9, n.1, p.9-15, 2001.

SILVEIRA, M.C.T.; PERES, N.B. Informações sobre plantas forrageiras C4 para cultivo em condições de deficiência de drenagem e tolerância a frio. Embrapa Pecuária Sul: Bagé, 2014. 36p. (Documentos / Embrapa Pecuária Sul, ISSN 1982-5390; 128).

SNYDER, R.L.; MELO-ABREU, J.P. Frost protection: fundamentals, practive and economics. Rome: Food and Agriculture Organization of the United Nations, 2005. 240p.

VIEIRA JUNIOR, N.A.; CARAMORI, P.H.; SILVA, M.A.A. et al. Minimum temperature differences between the meteorological screen and grass in radiative frost nights. Semina: Ciências Agrárias, v.39, n.6, p.2337-2350, 2018.

VILELA, D.; ALVIM, M. J. Produção de leite em pastagem de Cynodon dactylon. In: WORKSHOP SOBRE O POTENCIAL FORRAGEIRO DO GÊNERO CYNODON, 1996, Juiz de Fora. Anais... Juiz de Fora: Embrapa-CNPGL, 1996. p.77-91.

WENDT, W.; ROSA, O.S. Avaliação preliminar do efeito da geada sobre a fertilidade de espiga em trigo (Triticum aestivum L.), sob condições controladas. In: MOTA, F.S. da. (Ed.) Agrometeorologia do trigo no Brasil. Campinas: Sociedade Brasileira de Agrometeorologia, 1989. p.87-94.

Recebido para publicação em 12/03/2019 e aprovado em 11/09/2019. 